\title{
SHORT COMMUNICATION \\ The Beginning and Expansion of Flow Cytometry in Brazil
}

\author{
Sergio G Coutinho
}

\author{
Departamento de Protozoologia-Imunologia, Instituto Oswaldo Cruz, Av. Brasil 4365, 21045-900 \\ Rio de Janeiro, RJ, Brasil
}

The author describes and make comments on the favorable conditions that made possible the creation and organization of the first laboratory of flow cytometry in Brazil and South America installed at the Oswaldo Cruz Institute-Fiocruz, Rio de Janeiro, in November 1988.

Key words: flow cytometry in Brazil

The first flow cytometer in Latin America was installed at the Oswaldo Cruz Institute (IOC) in November 1988, becoming entirely functional within a short time. However, the idea of using such a potent instrument to perform multi parametric analysis of each individual cell or microorganism contained in a heterogeneous population had arisen earlier, in 1979/1980. By that time, I was at the WHO Immunology Research and Training Center in Lausanne, Switzerland, working on T cell-mediated immune responses against Leishmania using mice as an animal model. We frequently performed phenotypic analysis of parasite-specific $\mathrm{T}$ cell populations using flow cytometry. My familiarization with the method immediately brought me the perception of the extraordinary advantages it could provide in terms of accuracy and rapidity for studying different aspects of cell biology. That new tool should open many possibilities to be explored, allowing important progresses in the quality of our future scientific work.

To improve and expand information about flow cytometry in our scientific community, we decided to publish in a Brazilian journal, one of our scientific papers produced during that period in Lausanne. Thus the article entitled "Functional analysis of the murine T lymphocyte immune response to a protozoan parasite, Leishmania tropica" (Engers et al. 1983) was, as far I know, the first paper published in a South American journal on cell population analysis by flow cytometry.

Fax: +55-21-280.1589.

E-mail: coutinho@gene.dbbm.fiocruz.br

Received 9 August 1999

Accepted 28 October 1999
When I returned to Brazil, a new line of investigation on cell-mediated immunity in human American tegumentary leishmaniasis was established at the Oswaldo Cruz Institute. However, the progresses of our work had been impaired by the impossibility of a more precise cytofluorimetric cell analysis. Therefore, in several conversations with our directors, I frequently stressed the necessity of the acquisition of equipment for flow cytometry. I always mentioned its advantages, the broad and diversified field of investigation that would then be opened. The main problem always referred to the financial resources because of the high cost of the advanced type equipment we were interested in. During 1987/1988, Dr Carlos Morel, Director of the Oswaldo Cruz Institute, and the President of Fiocruz, were finally able to pool the resources of Fiocruz and of the National Social Security Institute (INSS) so that the equipment could be purchased. A scientist committee consisting of Sergio G Coutinho, Henrique Kriger, Henrique Lenzi, Samuel Gondenberg and Ricardo Ribeiro dos Santos, was then appointed to define the profile and configuration of the equipment to be acquired. It should be appropriate for research activities carried out at Fiocruz and other scientific institutions in Brazil, and for services, such as blood cell analysis of HIV positive patients.

The committee continued to be active even after the equipment was installed in our laboratory, but then with a new purpose: to define priorities among many requests for its use received from various departments of Fiocruz and from several universities in Rio de Janeiro, São Paulo, Rio Grande do Sul, Minas Gerais and other Brazilian states. With regard to services, the most frequent and important ones were those related to the follow up of Aids and of some patients from the $\mathrm{Na}$ tional Institute of Cancer. 
The flow cytometry methodology was thus definitively introduced and has been widely used at our Institute according to the objectives previously defined for the scientific, technologic and social areas. Moreover it has been used for teaching and for training personnel from this and other scientific Institutions. Courses on flow cytometry have also been taught to graduate students.

The equipment has been available for unrestricted use by the Brazilian scientific community. This collaborative policy was well characterized when the first two papers based on the use of the IOC flow cytometer were published by our laboratory and by a research group from another Institution respectively: (a) - "Analysis of the human $T$ cell responsiveness to purified antigens of Leishmania: lipophosphoglycan (LPG) and glycoprotein 63 (gp63)" (Mendonça et al. 1991) and (b) "Acute Trypanosoma cruzi infection differentially affects CD3 and Thy-1 cell activation" (Oliveira \& Gattass 1991).

The expansion of flow cytometry in Brazil and particularly at Fiocruz has been quite impressive during these ten years. Nowadays, there are three flow cytomers at IOC, and by this time, a new top quality apparatus has been acquired to replace the first equipment that has become obsolete, after all these years. The will and decision of $\mathrm{Dr} \mathbf{J}$ Rodrigues Coura, Director of the IOC, in consonance with the recently created Fiocruz Program for Flow Cytometry were fundamental to determine this new acquisition. This Program has become necessary to optimize and promote associations and cooperation among the various scientific groups working in this area at Fiocruz, since at present there are flow cytometers at Far-Manguinhos, at
Centro de Pesquisas Rene Rachou, in Belo Horizonte (MG), and at Centro de Pesquisas Gonçalo Muniz, in Salvador (BA).

During this period, several universities and research centers from different regions of the country have achieved capability and expertise in this matter. This rapid expansion has also been extended to private health services and laboratories, as should be expected considering the importance of the method for the diagnosis and follow up of many diseases including malignancies and those which affect the immune system.

A Flow Cytometry Club was created in 1994 to permit specialists to share their knowledge; four annual scientific meetings have already been organized, the last one in 1997. That year, the First IberoLatin-American Congresses of Flow Cytometry was held in Guarujá (SP) when the Latin American Society of Flow Cytometry was also created.

The extraordinary advancement of flow cytometry in Brazil and Latin America during these ten years is remarkable. All of us should be pleased to have participated in this incredible progress.

\section{REFERENCES}

Engers HD, Coutinho SG, Araújo Lima GM, Louis JA 1983. Funcional analysis of the murine T lymphocyte immune response to a protozoan parasite, Leishmania tropica. Mem Inst Oswaldo Cruz 78: 105-120.

Mendonça SCF, Russell DG, Coutinho SG 1991. Analysis of the human $\mathrm{T}$ cell responsiveness to purified antigens of Leishmania: lipophosphoglycan (LPG) and glycoprotein 63 (gp63). Clin Exp Immunol 83: 472-478.

Oliveira GA, Gattass CR 1991. Acute Trypanosoma cruzi infection differentially affects CD3 and Thy- 1 cell activation. Immunol Letters 28: 227-232. 